\title{
JOB LOSS, CREDIT CONSTRAINTS, AND CONSUMPTION GROWTH
}

\author{
Thomas F. Crossley and Hamish W. Low*
}

\begin{abstract}
We use direct evidence on credit constraints to study their importance for household consumption growth and for welfare. We distentangle the direct effect on consumption growth of a currently binding credit constraint from the indirect effect of a potentially binding credit constraint that generates consumption risk. Our data are focused on job losers. We find that less than 5\% of job losers experience a binding credit constraint, but those who do experience significant welfare losses, and consumption growth is $24 \%$ higher than for the rest of the population. However, even among those who are unconstrained and are able to borrow if needed, consumption responds to transitory income.
\end{abstract}

\section{Introduction}

$\mathrm{C}$ REDIT constraints faced by households have potentially important implications for efficacy of monetary and fiscal stimulus, the impact of transitory shocks, and more broadly for welfare and growth. As a result, the incidence and impact of such constraints is an empirical question of long-standing and continued importance (Hall \& Mishkin, 1982; Zeldes, 1989; Jappelli, 1990; Jappelli, Piske, \& Souleles, 1998; Gross \& Souleles, 2002; Leth-Petersen, 2010). A key challenge in this literature is that researchers rarely have direct observations on whether credit constraints are binding, and thus must typically infer the incidence of credit constraints from observed behavior, such as individuals' holding no liquid assets or the responsiveness of consumption to transitory shocks. This inference may be misleading and conclusions about the impact of credit constraints misstated. In this paper, we resolve this problem using an unusual Canadian survey of job losers that collects direct data on credit constraints, along with data on consumption growth and subjective experiences of financial hardship. The analysis of the impact of credit constraints using these data is particularly interesting for three reasons.

First, the data are unusually rich: the same individuals are asked about credit constraints and broad consumption choices. In the work most similar to this paper, Jappelli et al. (1998) use two-sample instrumental-variable methods to combine data on food expenditure from the PSID with measures of credit constraints from the Survey of Consumer Finances (SCF). Jappelli et al. argue that this combination of data provides a superior test for credit constraints relative to splitting a sample based on the presence of liquid asset holdings, as employed by Zeldes (1989) and Runkle (1991), and, more recently, by Dynarksi and Gruber (1997), Ziliak (1998), Johnson, Parker, and Souleles (2006), and Leth-Peterson (2010). Our data contain the same measures

Received for publication July 8, 2011. Revision accepted for publication May 14, 2013. Editor: Mark W. Watson.

* Crossley: Koc University, University of Essex, and Institute for Fiscal Studies; Low: University of Cambridge and Institute for Fiscal Studies.

For helpful comments, we are grateful to seminar participants at the Easter 2011 workshop of the Centre for Financial Analysis and Policy. For financial support, we thank the Social Science Humanities Research Council of Canada. of credit constraints as the SCF data studied by Jappelli et al., along with an alternative set of questions that asks directly about ability and desire to borrow at a point in time. Further, the same data contain measures of consumption growth, eliminating the need for two-sample procedures, and our data measure not only food expenditure but also total household expenditure. There is good evidence that food consumption is preferentially smoothed in the face of transitory income shocks (Browning \& Crossley, 2009) and so total expenditure provides a more convincing test of the impact of credit constraints. The same data include, in addition to direct measures of credit constraints and multiple measures of consumption growth, data on the subjective experience of financial hardship. Thus, we observe the complete chain from constraints, to behavior, to (subjectively experienced) welfare.

The second reason that our analysis is of interest is that we can address the questions of how much consumption smoothing occurs after job loss, how this is affected by credit constraints, and the value of unemployment insurance. This is related to the literature on the marginal propensity to consume out of current or transitory income: Browning and Crossley (2001) report that the marginal propensity to consume out of unemployment benefit income varies between 0 and .25 for different groups, where the groups are defined by family type and financial wealth. Sullivan (2008) and Bloemen and Stancanelli (2005), using measures of food consumption in U.S. and U.K. data, respectively, also document significant variation in the marginal propensity to consume out of current income across job losers with different wealth levels. Those without (liquid) assets are considered to be more likely to be constrained, and the fact that they have a higher marginal propensity to consume out of current income is taken to be confirmation of binding borrowing constraints.

This interpretation should be viewed with caution, however. As Jappelli (1990) and Jappelli et al. (1998) empha sized, asset levels are an imprecise measure of credit constraints. While those who carry forward liquid assets are clearly not currently constrained, they may be unable to borrow if they needed to and therefore have a stronger precautionary motive because of this potential constraint. As Carroll (2001) emphasized, this can lead to greater buffer stock holdings of wealth against income uncertainty. Further, the absence of assets does not necessarily imply a binding constraint; for example, it may reflect impatience or high current needs. Zeldes (1989) recognized at a theoretical level this distinction between a currently binding constraint and a potentially binding constraint. Gross and Souleles (2002) acknowledge that their evidence can partially be explained by a precautionary motive caused by a potential constraint. Leth-Petersen (2010) identifies consumption growth in Denmark as being due to a change in credit conditions, but without 
taking a stand on whether this is a direct effect or a precautionary effect. Our paper addresses this issue directly. We have direct measures both of whether individuals are currently constrained as well as whether they have the ability to borrow should they need to. Our direct measures of the availability of credit also allow us to assess how closely binding constraints are associated with zero wealth holdings, and they allow us to test whether consumption growth is associated with low assets or associated with a binding constraint.

The final reason this survey of job losers is of interest is that recent job losers are likely to be more credit constrained than the general population. Employment status is a key criterion that lenders consider, and investments in future earnings (either human capital or job search) are not collateralizable. A survey of job losers therefore increases our chances of finding evidence of credit constraints.

We find that a quarter of recent job losers could not borrow to raise current consumption. A smaller fraction (less than $5 \%$ ) reports that this constraint is binding: they would like to borrow but cannot. A binding credit constraint is likely to lead to more responsiveness to current income, and we show that those who experience a binding credit constraint exhibit significantly higher subsequent consumption growth than other job losers and are much more likely to report that the job loss was a financial hardship. Further, once we control for the presence of a binding constraint, assets have no significant effect on consumption growth.

By contrast, we show that even those who are able to borrow are responsive to current income and display excess sensitivity in consumption growth. While this result shows that the presence of binding credit constraints is not the complete story behind the response of consumption to current income, the magnitude of the response to current income among those able to borrow is substantially less than the effect on consumption growth of a binding constraint. This highlights that the important failures to smooth consumption are largely among a small number of job losers who experience a binding constraint. For these job losers, the welfare costs are substantial.

The next section outlines the theoretical framework that motivates our analysis. Section III describes our data. Section III presents our results, and section V concludes.

\section{Theoretical Framework}

We take a standard intertemporal optimization problem of a consumer (with stationary and intertemporally additive preferences), who faces a borrowing constraint: 1

$$
A_{t+1} \geq \underline{\mathrm{A}} \text {. }
$$

${ }^{1}$ For simplicity, we consider a borrowing constraint as being on the quantity that individuals can borrow. Alternatively, a constraint may be through the price that individuals can borrow at.
This yields the first-order condition:

$$
\frac{\partial u}{\partial c_{t}}-\mu_{t}=\beta R E_{t}\left[\frac{\partial u}{\partial c_{t+1}}-\mu_{t+1}\right]=\beta R E_{t}\left[\frac{\partial V_{t+1}}{\partial A_{t+1}}\right] .
$$

Consumption is given by $c_{t}$ and assets by $A_{t} ; \beta$ is the subjective discount factor, and $R$ reflects the market rate of return; $u$ denotes the per period utility (or "felicity") function; $V$ denotes a value function; and $\mu_{t}$ is the multiplier on the borrowing constraint. Equation (1) says that the marginal utility of consumption today (on the left) differs from the expected future marginal value of assets (on the right) by the multiplier $\left(\mu_{t}>0\right)$. The value of $\mu_{t}$ depends on the amount of resources (cash-in-hand or income) available in that period.

A binding credit constraint raises marginal utility and lowers consumption, today. Consumption growth (e.g., from a period of unemployment into a period of employment) is consistent with the relaxing of a binding credit constraint $\left(\mu_{t}>\mu_{t+1}\right)$. However, it can also be attributed to considerations on the right-hand side of equation (1). First, if the market rate of return exceeds the subjective discount factor so that $\beta R>1$, marginal utility falls over time and, hence, consumption rises. Second, because of the concavity of the felicity (and value) function, uncertainty about future consumption lowers expected marginal utility and so generates consumption growth. To see the latter effect more clearly, we assume constant relative risk aversion (CRRA) preferences and that $\beta R=1$, and we derive an expression for consumption growth. Note that we can write both one-period-ahead and two-period-ahead Euler equations:

$$
\begin{aligned}
& \left(c_{t}\right)^{-\gamma}-\mu_{t}=E_{t}\left[\frac{\partial V_{t+1}}{\partial A_{t+1}}\right], \\
& \left(c_{t-1}\right)^{-\gamma}-\mu_{t-1}=E_{t-1}\left[\frac{\partial V_{t+1}}{\partial A_{t+1}}\right],
\end{aligned}
$$

so that

$$
\left(\frac{c_{t}}{c_{t-1}}\right)^{-\gamma}=\frac{E_{t}\left[\frac{\partial V_{t+1}}{\partial A_{t+1}}\right]+\mu_{t}}{E_{t-1}\left[\frac{\partial V_{t+1}}{\partial A_{t+1}}\right]+\mu_{t-1}}
$$

and:

$$
\begin{aligned}
\log c_{t}-\log c_{t-1}= & -\frac{1}{\gamma}\left[\log \left(E_{t}\left[\frac{\partial V_{t+1}}{\partial A_{t+1}}\right]+\mu_{t}\right)\right. \\
& \left.-\log \left(E_{t-1}\left[\frac{\partial V_{t+1}}{\partial A_{t+1}}\right]+\mu_{t-1}\right)\right]
\end{aligned}
$$

Consumption growth will respond to changes (between $t-1$ and $t$ ) in the multiplier on the borrowing constraint and to changes (between $t-1$ and $t$ ) in the expectation of the marginal value of wealth at $t+1$, and subsequent dates. Recalling 


$$
\text { that } \begin{aligned}
& \frac{\partial V_{t+1}}{\partial A_{t+1}}=\frac{\partial u}{\partial c_{t+1}}-\mu_{t+1}=c_{t+1}^{-\gamma}-\mu_{t+1} \text { gives } \\
& \qquad \begin{aligned}
\log c_{t}-\log c_{t-1}= & -\frac{1}{\gamma}\left[\log \left(E_{t}\left[c_{t+1}^{-\gamma}-\mu_{t+1}\right]+\mu_{t}\right)\right. \\
& \left.-\log \left(E_{t-1}\left[c_{t+1}^{-\gamma}-\mu_{t+1}\right]+\mu_{t-1}\right)\right],
\end{aligned}
\end{aligned}
$$

and, taking a first-order approximation around values at $t-1$,

$$
\begin{aligned}
& \log c_{t}-\log c_{t-1} \\
& \approx-\frac{1}{\gamma c_{t-1}^{-\gamma}}\left(\begin{array}{c}
E_{t}\left[c_{t+1}^{-\gamma}-\mu_{t+1}\right]-E_{t-1}\left[c_{t+1}^{-\gamma}-\mu_{t+1}\right] \\
+\mu_{t}-\mu_{t-1}
\end{array}\right) .
\end{aligned}
$$

Consumption growth will be higher for individuals who face a binding borrowing constraint in period $t-1$ (i.e., $\mu_{t-1}>0$ ). Consumption growth will also be affected by any change (between $t-1$ and $t$ ) in the expectation of the future marginal value of assets $\left(E_{t-1}\left[\frac{\partial V_{t+1}}{\partial A_{t+1}}\right]\right.$ to $\left.E_{t}\left[\frac{\partial V_{t+1}}{\partial A_{t+1}}\right]\right)$. A decrease in the expected marginal value of assets decreases the benefit of deferring spending further into the future, consumption in period $t$ rises, and consumption growth is faster. The expected marginal value of assets depends on the expected future value of the multiplier on the borrowing constraint, $\mu_{t+1}$, and so consumption growth increases in response to a decrease in the perceived probability that the borrowing constraint will bind in the future. Of course, consumption growth will also respond to any other factors that change the expected marginal value of wealth.

We can consider within this framework the effect of a credit market liberalization. ${ }^{2}$ For households that, in the absence of the liberalization, faced binding constraints, consumption after the liberalization will boom, leading to faster consumption growth through the liberalization. In terms of equation (2), this is the effect of a reduction in $\mu_{t}$. However, financial liberalization has another effect on consumption growth: relaxing the probability of credit constraints binding at some point in the future. In equation (2), this is the updating of expectations about the marginal value of assets in the future: savings become less valuable (because an alternative selfinsurance mechanism is now available) and consumption will increase even if credit constraints were not currently binding at the time of the reform. Of course, this would not occur in an environment in which there was no possibility of a binding credit constraint. Evidence that financial liberalization leads to a consumption boom therefore establishes only that the possibility of a (current or future) binding credit constraint was a feature of the economic environment. For example, Leth-Peterson (2010) finds evidence of a consumption boom (albeit small) following financial liberalization in Denmark but remains agnostic as to the relative importance of these two channels. This point is similar to the more general argument in section I: a high marginal propensity to consume out

\footnotetext{
${ }^{2}$ Here we focus on the immediate (transition) effects of a liberalization Of course, in the steady state, a more liberal credit market will be associated with smoother consumption than otherwise.
}

of those with low liquid assets does not necessarily mean that constraints are currently binding.

For our analysis, the key implication is that there are two possible sources of rapid consumption growth among recent job losers: (a) the relaxation of currently binding credit constraints and (b) the resolution of uncertainty over future resources in general, and, in particular, over the possibility of being credit constrained in the future. In our empirical work, we have direct measures both of whether individuals are currently constrained as well as whether they have the ability to borrow should they need to. We can therefore see whether excess consumption growth is limited to those with currently binding constraints or whether a lack of access to credit per se has an impact on consumption growth.

Finally, we note that the welfare losses of failing to smooth consumption are proportional to the square of consumption growth for agents of a given age. This follows from a standard certainty-equivalence argument (following Lucas, 1987). With $\beta R=1$, an unconstrained and fully insured consumer will choose a constant consumption stream: $c_{t}=\bar{c}$. To economize on notation, set $\beta=R=1$. Suppose now the consumer is constrained to consume $c_{1}=\bar{c}(1-\Delta)$ in the current period but will be able to maintain a smooth consumption path from the next period on. The future constant consumption path must satisfy the intertemporal budget constraint, so $c_{t}=\bar{c}\left(1+\frac{\Delta}{T-1}\right)$ for $t=2,3, \ldots, T$. Note that $\Delta$ is approximately the consumption growth rate from $t=1$ to $t=2$ (for large $T$ or small $\Delta$ ). Let $\delta$ be the fraction of the constant consumption stream $(\bar{c})$ that the consumer would forgo in order to smooth consumption over all $T$ periods:

$$
\begin{aligned}
\operatorname{Tu}(\bar{c}(1-\delta))= & u(\bar{c}(1-\Delta)) \\
& +(T-1) u\left(\bar{c}\left(1+\frac{\Delta}{T-1}\right)\right) .
\end{aligned}
$$

Assume that CRRA preferences $u(c)=\frac{c^{1-\gamma}}{1-\gamma}$, take a firstorder Taylor-series approximation around $c_{t}=\bar{c}$ on the lefthand side of equation (3) and a second-order approximation around $c_{t}=\bar{c}$ of both terms on the right-hand side. This gives

$$
\delta=\frac{1}{2} \gamma \Delta^{2}\left(\frac{1}{T-1}\right) .
$$

Thus, among consumers with the same time horizon $(T)$, which is naturally interpreted as age, the welfare loss due to the constraint (measured as the fraction of smooth consumption the consumer would forgo to have a smooth path) is proportional to the square of subsequent consumption growth. ${ }^{3}$ With this analysis in mind, we interpret post-job loss consumption growth as an index of the welfare loss associated with job loss. Because our data also contain self-reports of the financial hardship of job loss, we are able to corroborate this interpretation of the data.

\footnotetext{
${ }^{3}$ This differs from the usual Lucas formula because we are considering a single episode of failure to smooth rather than ongoing volatility.
} 


\section{Data}

The 1995 Canadian Out of Employment Panel (COEP) surveyed individuals who separated from jobs in the first half of $1995 .{ }^{4}$ Respondents were interviewed in the last quarter of 1995 (around three quarters after job loss) and then a second time five quarters after job loss. Interviews collected information about respondents' circumstances at the interview dates and retrospectively about their circumstances prior to the end of the relevant job and over the intervening periods (between job separation and the first interview and between the two interviews). Information was collected about respondents' work, training, and job search and about their household composition, consumption, income, and finances.

Respondents to the survey number 7,818, but these cover a range of job separation types, including quits, dismissals, separations due to illness, and temporary and permanent layoffs. In this paper, we focus on a sample of job losers who, at the time of job loss, were prime-aged, lived in a nuclear family (alone, with a spouse, or spouse and children), and were the primary earner in their household. Experience with this data suggests that the quality of the survey responses on household finances is lower among respondents in other family types (e.g., living with their parents or with unrelated adults). The job loss of primary earners is of particular interest, and in focusing on primary earners, we are following much of the previous literature (e.g., Dynarski and Gruber, 1997).

Our sample is of 2,922 individuals who lived in a nuclear family and were the primary earners in their households. Of these respondents, 1,659 were employed at the time of the first interview. The other 1,263 were not working at the time of the interview, though some of these had spells of employment between the initial job loss and the interview. ${ }^{5}$ For those not working at the time of the interview, monthly net household income was on average $22 \%$ below the month prior to job loss. A quarter reported losses of net household income in excess of $39 \%$. These numbers reflect the replacement income offered by the unemployment benefit system, the progressivity of income taxes, and the fact that many households had second earners. (For further discussion, see Browning \& Crossley, 2009.)

Crucial to our analysis is the unusually good credit constraint measures in the 1995 COEP. The survey asked respondents two sets of questions about their ability to borrow. They were asked subjective questions about the ability and desire to borrow at the interview date, as follows:

- "If you needed it, COULD you borrow money from a friend, family, or a financial institution in order to increase your household expenditures?"

\footnotetext{
4 The survey was conducted by the Special Surveys Division of Statistics Canada; further details are available at http://www.statcan.ca/english/IPS /Data/72M0001XCB.htm.

5 Some of our regression analyses are based on slightly smaller samples due to the inevitable item nonresponse in a large and comprehensive survey.
}

If the answer to this question was negative, the respondent was then asked:

- "Suppose you COULD borrow money from one of these sources at $11 \%$ interest per year, to be paid back starting in one year. WOULD you borrow money to increase your weekly spending on household expenses?"6

A question similar to the first of these was previously posed to low-income households in Chicago (Mayer \& Jencks, 1989). We take the answers to the first question as informative about access to credit. If a respondent says no to the first question and yes to the second, we take that person to be reporting that he or she faces a currently binding credit constraint.

Second, respondents were asked a series of questions about credit applications and the outcomes of those applications over an interval of time. These questions are similar to the U.S. Survey of Consumer Finance questions studied by Jappelli (1990) and are as follows:

- "At any time since your job ended on [date of job loss] did you or any member of your household apply for a loan at a bank or financial institution, or for credit with any credit company?" (Applied)

- "Were any of your requests for credit or a loan turned down?" (Declined)

- "Were you, or any member of your household, given as much credit as you applied for?" (Not full amount)

- "Were you later able to obtain the full amount you requested by reapplying to the same institution or by applying elsewhere?" (Got later)

- "Was there any time since [date of job loss] that you or any member of your household thought of applying for credit at a particular place, but changed your mind because you thought you might be turned down?" (Discouraged)

We refer to these as the objective questions because they refer to actual (past) events rather than to hypotheticals. ${ }^{7} \mathrm{We}$ now turn to an analysis of these data.

\section{Results}

\section{A. The Incidence of Credit Constraints among Job Losers}

Responses to the subjective questions are summarized in the top panel of table 1 . Among respondents not working at the time of interview, more than $30 \%$ report that they could not borrow. The corresponding number for those back in employment is almost 10 percentage points lower. Overall, about a quarter of recent job losers report no access to

${ }^{6}$ Nominal prime interest rate at this time in Canada was about $7 \%$.

${ }^{7}$ A limitation of these measures is that they are discrete: either an individual is constrained or not, and the constraint is defined in terms of quantity. In practice, credit constraints might mean differential borrowing rates, and while individuals may report being unable to borrow at $11 \%$, they may be able to borrow at a higher rate. Our data cannot identify this distinction. 
TABle 1.-CRedit Market Access And CRedit Constrained

\begin{tabular}{|c|c|c|c|}
\hline \multicolumn{4}{|c|}{ Subjective Assessment of the Ability to Borrow } \\
\hline & Not Employed & Employed & Pooled \\
\hline Currently unable to borrow & $31.2 \%$ & $23.0 \%$ & $26.5 \%$ \\
\hline Currently constrained: & & & \\
\hline of those unable to borrow & $13.1 \%$ & $14.4 \%$ & $13.8 \%$ \\
\hline of sample & $4.0 \%$ & $3.3 \%$ & $3.6 \%$ \\
\hline Number of observations & 1,263 & 1,659 & 2,922 \\
\hline \multicolumn{4}{|c|}{ Objective Assessment of the Ability to Borrow } \\
\hline & Label & Denominator & Pooled \\
\hline Applied for credit & (1) & Sample & $24.4 \%$ \\
\hline Declined & (2) & (1) & $24.6 \%$ \\
\hline Not full amount & (3) & (1)-(2) & $4.5 \%$ \\
\hline Got later ${ }^{\mathrm{a}}$ & (4) & $(2)+(3)$ & $11.6 \%$ \\
\hline \multirow[t]{2}{*}{ Constrained (A) } & $(2)+(3)-(4)$ & (1) & $24.6 \%$ \\
\hline & & Sample & $6.0 \%$ \\
\hline \multirow[t]{2}{*}{ Discouraged } & (5) & Nonapplicants & $11.1 \%$ \\
\hline & & Sample & $8.4 \%$ \\
\hline Constrained (B) & $(A)+(5)$ & Sample & $14.3 \%$ \\
\hline Number of observations & & & \\
\hline
\end{tabular}

Self-reports, 1995 COEP, first Interview (third quarter after separation from a job).

${ }^{\text {a }}$ There are a large number of missing values to this question. We treat these as a negative response. This is the only question to which there is significant nonresponse.

credit. Of those who report that they are unable to borrow, only a fraction (13\% among those not working) report that they would borrow if they could. Thus, only a small fraction of the sample report being "constrained" in the sense of a Euler equation violation. However, as outlined in section B, uncertainty about future employment and the possibility that credit constraints may bind in the future may be dampening the desire to borrow.

The bottom panel of table 1 summarizes responses to the objective questions. About a quarter of recent job losers applied for some kind of credit before the first interview. ${ }^{8}$ Of those, about a quarter were constrained in the sense that their application was declined or they did not get the full amount and they were not later able to get the full amount. Thus, about $6 \%$ of the full sample are constrained by this definition. Following Jappelli, we also consider a broader definition of constrained that includes those who did not apply because they anticipated that an application would not be successful (the discouraged). These are about $8 \%$ of the sample, so that about $14 \%$ of the sample are constrained by this broader definition. In comparison, Jappelli (1990) finds $19 \%$ of households in the 1983 U.S. Survey of Consumer Finance report being constrained in this sense over a period of several years prior to the interview.

Figure 1 illustrates the age patterns in our measures of credit access and credit constrained. The top panel is based on the "subjective" questions. The sample is divided into three age groups $(26-35,36-45$, and 46-55), and each group

\footnotetext{
${ }^{8}$ The data contain some information on the type of credit our respondents applied for. Personal loans, car loans, and credit cards were the most common. Although the respondents could list up to three different kinds of credit, more than $90 \%$ listed only one type. Thus, we can also calculate rough rejection rates by type of credit. These were much higher for unsecured debt (credit cards and consolidation loans) than for secured debt (car loans and mortgages).
}
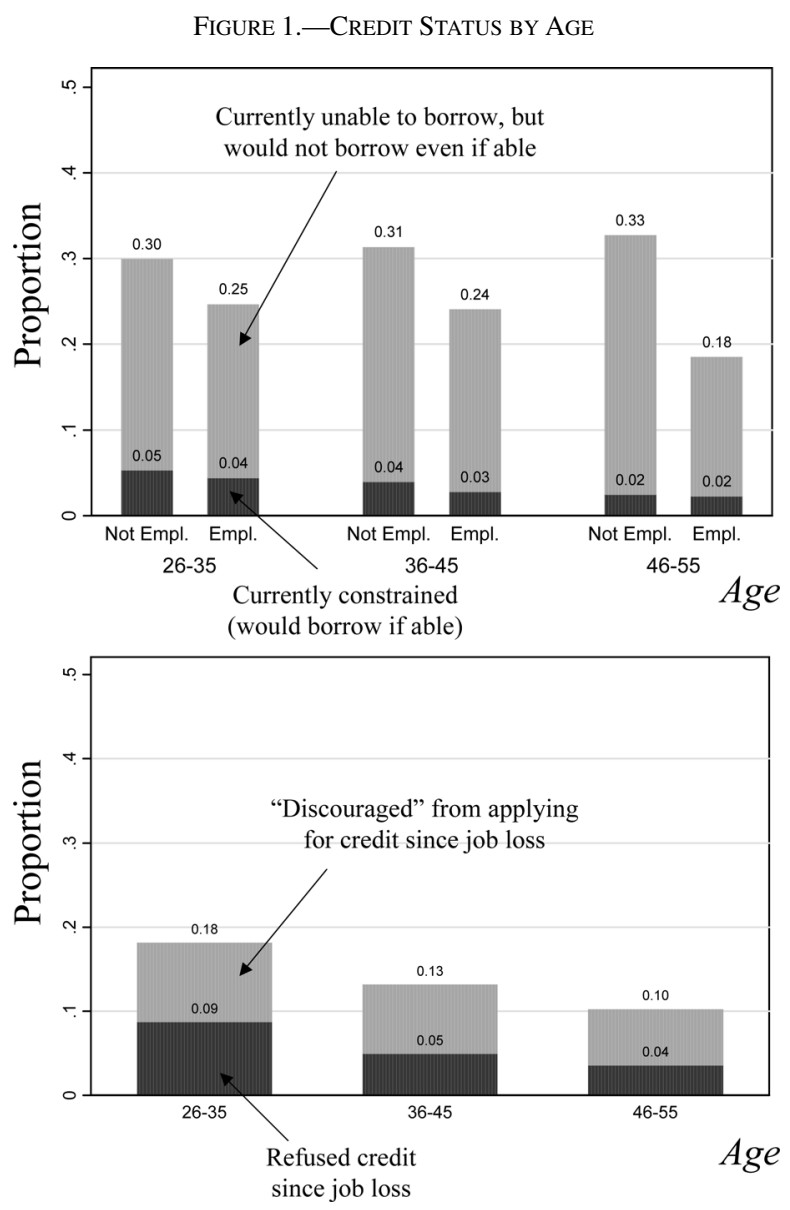

The top graph reports responses to the subjective questions on credit status. The bottom graph reports responses to the objective questions on credit status. The subjective questions refer to status at the time of the interview, and we split the sample by current employment status. The objective questions refer the interview, and we split the sample by current employment status. The objective questions refer to the above the lower section on each bar gives the size of the lower section. The number at the top of each bar gives the total for that age group (by employment status for the top graph).

is divided into those who are and are not employed at the time of the (first) interview. Among respondents aged 26 to 35 , not in work at the interview date, $30 \%$ could not borrow and $5 \%$ would if they could. The fraction who report that they could not borrow falls with age among the employed but rises with age among those not in work. The fraction who are constrained (can't borrow and would) falls with age for both the employed and unemployed.

The lower panel of figure 1 is based on the "objective" questions. We divide the sample into the same three age categories. However, as these questions refer to anytime since the job loss, we do not divide by current employment status. Among the youngest group, $9 \%$ experience a binding borrowing constraint in the sense of being unable to obtain credit for which they applied, while $18 \%$ report being constrained in the broader sense of either being unable to obtain credit for which they applied or deciding not to apply in anticipation of the application being unsuccessful. By either the broad or narrow measure, the incidence of (binding) borrowing constraints falls with age. Relative to the subjective questions, the objective questions suggest a greater incidence of binding 
TABLE 2.-ChARACTERISTICS OF THE CREDIT CONSTRAINED

\begin{tabular}{lrrr}
\hline & $\begin{array}{c}\text { Unable } \\
\text { to Borrow }\end{array}$ & $\begin{array}{c}\text { Unable to Borrow } \\
\text { and Would }\end{array}$ & $\begin{array}{c}\text { Rejected or } \\
\text { Discouraged }\end{array}$ \\
\hline Male & $\mathbf{- 0 . 0 4 8}(.024)$ & $0.001(.007)$ & $-0.001(.017)$ \\
Age & $\mathbf{0 . 0 4 0}(.019)$ & $0.000(.006)$ & $-0.019(.014)$ \\
Age 45 & $\mathbf{- 0 . 1 5 1}(.063)$ & $-0.024(.023)$ & $-0.033(.050)$ \\
High school & $-\mathbf{0 . 0 5 1}(.022)$ & $-\mathbf{0 . 0 1 5}(.007)$ & $-0.005(.016)$ \\
University or college & $-\mathbf{0 . 0 8 1}(.025)$ & $-\mathbf{0 . 0 2 3}(.006)$ & $-\mathbf{0 . 0 5 2}(.018)$ \\
Spouse present & $-0.011(.031)$ & $-0.006(.010)$ & $-0.033(.024)$ \\
Children present & $0.005(.023)$ & $0.010(.008)$ & $0.017(.017)$ \\
Visible minority & $\mathbf{0 . 0 7 7}(.025)$ & $\mathbf{0 . 0 2 1}(.010)$ & $\mathbf{0 . 0 5 6}(.020)$ \\
Quit & $-0.041(.043)$ & $0.008(.017)$ & $0.00(.034)$ \\
Fired & $0.095(.066)$ & $0.030(.029)$ & $0.082(.055)$ \\
Ill & $-0.061(.041)$ & $0.014(.018)$ & $0.044(.038)$ \\
Own home & $-\mathbf{0 . 2 2 4}(.033)$ & $-\mathbf{0 . 0 7 5}(.022)$ & $-\mathbf{0 . 1 1 4}(.027)$ \\
Mortgage & $\mathbf{0 . 1 1 1}(.032)$ & $\mathbf{0 . 0 2 8}(.017)$ & $0.020(.025)$ \\
Spouse employed & $-0.027(.025)$ & $-0.005(.008)$ & $-0.026(.019)$ \\
Liquid assets & $\mathbf{- 0 . 1 0 5}(.020)$ & $-0.010(.007)$ & $-\mathbf{0 . 0 3 3}(.015)$ \\
Other debt & $0.027(.020)$ & $\mathbf{0 . 0 1 6}(.006)$ & $\mathbf{0 . 0 8 9}(.014)$ \\
Employed & $-\mathbf{0 . 0 9 7}(.020)$ & $-0.009(.007)$ & \\
Pseudo- $R^{2}$ & 0.075 & 0.121 & 0.091 \\
& Mean $=0.27$ & Mean $=0.042$ & Mean $=0.147$ \\
\hline Marginal Effects from probit. Bold figures are significant at $10 \%$ Standard errors in parentheses.
\end{tabular}

constraints at all ages. This is quite natural because the former refer to the time of the interview, while the latter refer to any time since the job loss.

To summarize the correlates of being credit constrained, we estimated a series of probit models. We have a set of predictor variables including just characteristics of respondents and their households, as well as information on the type of job separation and household financial circumstances at the time of job loss. The results are presented in table 2 .

The first column of table 2 presents empirical (probit) models of the response to the "could borrow" question. We have coded a negative response as 1 , and so these are models of the probability that the respondent is unable to borrow. Women are more likely to be unable to borrow, as are the less educated and visible minorities. Households with liquid assets or owning their home are more likely to be able to borrow. The home ownership effect is partially offset by having a mortgage. Current unemployment appears to have an independent effect (reducing ability to borrow) even after controlling for other factors. ${ }^{9}$ These effects are economically significant.

In the second column of table 2 we turn from the issue of whether a household could borrow to the issue of whether they face (or have faced) a binding constraint. Here a respondent is coded 1 if unable to borrow and would like to. Visible minorities, those with little education, and non-home owners are more likely to experience a binding borrowing constraint. The presence of liquid assets does not affect the probability of a currently binding constraint, an issue we return to.

\footnotetext{
${ }^{9} \mathrm{We}$ initially split the sample into respondents who were not employed at the interview date and those who were. Likelihood ratio tests indicated that we could not reject pooling the employed and unemployed (allowing for an intercept shift) in estimating the probit models reported here.
}

Table 3.-Comparing Direct Measures of Credit Constraints with ASSET HOLDINGS

\begin{tabular}{|c|c|c|c|c|}
\hline & Correlates & $\begin{array}{c}\text { Observed } \\
\text { Agreement } \\
P_{0}\end{array}$ & $\begin{array}{c}\text { Expected } \\
\text { Agreement } \\
P_{e}\end{array}$ & $\begin{array}{c}\text { Kappa (SE) } \\
\frac{P_{0}-P_{e}}{1-P_{e}}\end{array}$ \\
\hline \multirow{4}{*}{$\begin{array}{l}\text { Hold no } \\
\text { assets, } \\
A=0\end{array}$} & Unable to borrow & 0.57 & 0.46 & $\mathbf{0 . 1 9 2}(.017)$ \\
\hline & Currently constrained & 0.46 & 0.43 & $\mathbf{0 . 0 4 8}(.007)$ \\
\hline & Refused credit & 0.56 & 0.54 & $\mathbf{0 . 0 3 4}(.011)$ \\
\hline & or discouraged & 0.56 & 0.53 & $\mathbf{0 . 0 5 9}(.016)$ \\
\hline \multirow{4}{*}{$\begin{array}{l}\text { Hold } \\
\qquad \text { assets, } \\
\qquad A<2 * \frac{y}{12}\end{array}$} & Unable to borrow & 0.47 & 0.40 & $\mathbf{0 . 1 2 3}(.013)$ \\
\hline & Currently constrained & 0.31 & 0.29 & $\mathbf{0 . 0 2 5}(.005)$ \\
\hline & Refused credit & 0.37 & 0.34 & $\mathbf{0 . 0 3 3}(.007)$ \\
\hline & or discouraged & 0.42 & 0.37 & $\mathbf{0 . 0 6 7}(.011)$ \\
\hline
\end{tabular}

The Kappa statistic measures the extent of agreement between two different measures of a discrete variable. Let $f(x, y)$ be the empirical joint distribution of these two measures, $x$ and $y$, which in our case take values of 0 or 1 . Let $f_{x}(x)$ be the empirical marginal distribution of measure $x$ and, similarly, $f_{y}(y)$. The observed proportion of agreement is $P_{0}=f(1,1)+f(0,0)$. The expected proportion of agreement (given the marginal distributions) is $P_{e}=f_{x}(1) f_{y}(1)+f_{x}(0) f_{y}(0)$. The kappa statistic is

$$
\kappa=\frac{P_{0}-P_{e}}{1-P_{e}}
$$

If the two measures agree perfectly and so $P_{0}=1$, then $\kappa=1$. The key factor that the kappa statistic adjusts for is that the expected proportion of agreement varies with the marginal distributions. If the observed agreement equals the expected agreement, $P_{0}=P_{e}$ and $\kappa=0$. The standard errors reported (in parentheses) agreement equals the expected agreement, $P_{0}=P_{e}$ and $\kappa=0$. The standard errors reported (in parentheses)
assume that the measures are provided by two independent assesors, whereas in our sample, the different assume that the measures are provided by two independent assesors, whereas in our sample, the different
measures are provided by the survey respondent. Subject to this caveat, bold indicates significance at $10 \%$. See also StataCorp (2009).

The third column of table 2 reports estimates of a probit model of the alternative measure of constrained, which is based on the objective questions (the broad measure, including "discouraged"). Once again, the less educated and visible minorities are more likely to be constrained. Households with liquid assets or owning their home are less likely to be constrained on this measure. Preexisting unsecured debt increases the likelihood of being constrained.

A natural question is whether our measures of borrowing constraints identify the same set of households as traditional approaches (based on wealth or liquid asset measures). Table 3 addresses this question. We construct two measures: whether the household had any liquid assets at all and whether they had at least two months of usual income in liquid assets. The latter is similar to the measure used by Zeldes (1989), Runkle (1991), Ziliak (1998), Johnson, Parker, and Souleles (2006), and Leth-Peterson (2010). We construct both of these measures at job loss and at the first interview. The first column of table 3 gives the actual agreement between the various measures: the fraction of the sample for which a pair of measures takes the same values (note that all the measures are binary). In considering the agreement between two binary measures, it is important to note that the further the means of the two measures are from .5, the greater the degree of agreement one would expect to arise simply by chance. The second column of table 3 gives the degree of agreement between each pair of measures that one would expect to arise by chance. The third column of table 3 gives the kappa statistic, which measures the degree of actual agreement, accounting for the degree of agreement that would arise by chance. A value of 0 indicates the same agreement as would arise by chance. A value of 1 indicates complete agreement. Table 3 illustrates a statistically significant degree of agreement between all the pairs of measures, but agreement is by no means perfect. 


\begin{tabular}{lrr}
\multicolumn{3}{c}{ TABle 4.- COnsumption GrowTH } \\
\hline \hline \multicolumn{2}{c}{$\Delta \ln C_{t+1}$} \\
\hline Constant & $-0.023(.035)$ & $-0.015(.035)$ \\
Age & $-\mathbf{0 . 0 9 8}(.027)$ & $-\mathbf{0 . 1 0 3}(.028)$ \\
$\Delta$ ln (Household size $)_{t+1}$ & $\mathbf{0 . 3 1 0}(.100)$ & $\mathbf{0 . 3 0 1}(.102)$ \\
Unable to borrow & $-0.023(.047)$ & $-0.034(.048)$ \\
Binding constraint & $\mathbf{0 . 2 4 8}(.100)$ & $\mathbf{0 . 2 7 1}(.103)$ \\
$A_{t}=0$ & $0.049(.043)$ & $0.043(.044)$ \\
$\Delta$ Employment & & $\mathbf{0 . 0 7 7}(.041)$ \\
Number of observations & 1,916 & 1,855 \\
$R^{2}$ & 0.018 & 0.020 \\
\hline
\end{tabular}

Bold indicates significance at $10 \%$. Standard errors in parentheses. Age is measured in decades as deviations from age 40 . This means that the constant should be interpreted as the consumption growth rate of a 40-year-old with no change in household size, no change in employment status, and all the dummy variables equal to 0 (i.e., able to borrow)

Whether the household has any assets seems to be a slightly better measure of whether they face borrowing constraints than whether they had two months of assets. On balance, our subjective and objective measures of borrowing constraints agree more strongly with each other than with the asset measures.

\section{B. Credit Constraints, Consumption Growth, and Financial Hardship}

The central element in our empirical analysis is to examine the consumption growth of households between the first interview in the third quarter after job loss and second interview in the fifth quarter after job loss. Consumption growth is defined as the change in the logarithm of total expenditure. This is divided by the number of weeks between the first and second interview to give an annual rate. Having a measure of total expenditure is another strong feature of these data. As discussed in Browning and Crossley (2009), food expenditure, which is used extensively in this literature, is likely to be preferentially smoothed. ${ }^{10}$

In tables 4 and 5, we report a series of consumption growth regressions. The first column of table 4 reports a regression of consumption growth on a constant, age, the change in household size between the first and second interviews, and dummy variables capturing the responses to the subjective questions regarding ability and desire to borrow at the first interview. The subjective questions are the natural ones to use here because of the timing: they pertain to borrowing constraints at the first interview, and we are modeling consumption growth from the first interview to the second one.

Those who report a binding constraint (they could not borrow but would if they could) exhibit very high consumption growth. Their consumption growth is statistically (and economically) different from the rest of the sample. The consumption growth of those who say they could not

\footnotetext{
10 Total expenditure in the survey is measured in a single recall question. This measure has been used in Browning and Crossley $(2001,2009)$. It is validated against data from a detailed expenditure survey in Browning et al. (2003).
}

borrow but are not constrained is not statistically different from those who say they could borrow. Further, when we control for access to credit, having no liquid wealth $\left(A_{t}=0\right)$ is not a significant determinant of consumption growth.

A possible concern here is that those facing binding credit constraints at interview 1 are less likely to be back in employment at interview 1 (see table 2). If leisure and consumption are nonseparable, then differences in consumption growth could be related to differences in employment growth. This explanation of the high consumption growth of the constrained would require that consumption and leisure are (Frisch) substitutes (or, equivalently, that consumption and employment are complements, for example, if there are expenditures associated with working). In the second column of table 4 we address this possibility by augmenting the specification of the first column by conditioning on employment growth. This changes the coefficients on other variables very little; in particular, it leads to a small increase in the difference in consumption growth rates between those reporting a binding constraint and the rest of the sample.

A second possible issue with the results in table 4 is discount rate heterogeneity. As noted in section 2, a theoretically plausible explanation for (persistent) consumption growth is patience: a low discount rate. However, patience leads to wealth accumulation. As documented in tables 2 and 3 , those reporting binding borrowing constraints are, conditional on age, less likely to own homes and less likely to hold liquid assets. Thus, the credit constrained are likely to be impatient and should, if anything, have unusually low (or even negative) consumption growth because of this revealed desire to bring consumption forward in time. The excess consumption growth documented in table 4 cannot be attributed to discount rate heterogeneity. In fact, if the credit constrained are more impatient than average, the excess consumption growth documented in table 4 should be taken as a lower bound for the effect of the borrowing constraint.

In table 5 we turn to consumption growth regressions that have the form of classic excess sensitivity tests. In particular, we regress consumption growth (between interview 1 and 2) on a constant, age, the change in household size, and the logarithm of lagged income (income at interview 1). The idea is that to the extent that it is in the information set at the first interview, lagged income should not predict consumption growth between the first and second interview.

Starting with the first column and moving right, we estimate this model on increasingly selected samples. The first column reports estimates for the whole sample, the second column excludes just those who report a binding constraint, and the estimates in the third column exclude all those who report being unable to borrow. Thus, this table examines how consumption growth varies with lagged income "within group." Here our empirical strategy is very similar to that of Jappelli et al. (1998) except that we have exact (rather than 
TABLE 5.-CONSUMPTION GROWTH WITHIN GROUPS

\begin{tabular}{|c|c|c|c|c|c|c|}
\hline \multirow[b]{2}{*}{ Sample } & \multicolumn{6}{|c|}{$\Delta \ln C_{t+1}$} \\
\hline & All & $\begin{array}{c}\text { Without } \\
\text { Binding } \\
\text { Constraint }\end{array}$ & $\begin{array}{l}\text { Able to } \\
\text { Borrow }\end{array}$ & All & $\begin{array}{c}\text { Without } \\
\text { Binding } \\
\text { Constraint }\end{array}$ & $\begin{array}{l}\text { Able to } \\
\text { Borrow }\end{array}$ \\
\hline Constant & $\begin{array}{l}0.004 \\
(.027)\end{array}$ & $\begin{array}{l}-0.0020 \\
(.021)\end{array}$ & $\underset{(.025)}{-0.0088}$ & $\begin{array}{l}0.008 \\
(.021)\end{array}$ & $\begin{array}{l}0.002 \\
(.022)\end{array}$ & $\begin{array}{l}0.0145 \\
(.0259)\end{array}$ \\
\hline Age & $\underset{(.027)}{-\mathbf{0 . 1 0 3}}$ & $\underset{(.028)}{-\mathbf{0 . 0 9 6}}$ & $\underset{(.032)}{-\mathbf{0 . 1 0 0}}$ & $\begin{array}{l}-\mathbf{0 . 1 0 8} \\
(.028)\end{array}$ & $\underset{(.028)}{-\mathbf{0 . 1 0 1}}$ & $\underset{(.033)}{-\mathbf{0 . 1 0 4}}$ \\
\hline$\Delta \ln ($ Hhd Size $)$ & $\underset{(.100)}{\mathbf{0 . 2 9 2}}$ & $\begin{array}{l}\mathbf{0 . 2 8 0} \\
(.107)\end{array}$ & $\underset{(.122)}{\mathbf{0 . 3 4 7}}$ & $\underset{(.203)}{\mathbf{0 . 2 8 4}}$ & $\underset{(.109)}{\mathbf{0 . 2 6 2}}$ & $\begin{array}{l}\mathbf{0 . 3 1 7} \\
(.127)\end{array}$ \\
\hline $\ln y_{t}$ & $\underset{(.037)}{-\mathbf{0 . 0 7 1}}$ & $\underset{(.037)}{-\mathbf{0 . 0 7 0}}$ & $\underset{(.044)}{-\mathbf{0 . 0 7 8}}$ & $\underset{(.038)}{-\mathbf{0 . 0 6 5}}$ & $\begin{array}{l}-0.059 \\
(.039)\end{array}$ & $\underset{(.045)}{-\mathbf{0 . 0 6 9}}$ \\
\hline$\Delta$ Participation & & & & $\begin{array}{l}0.064 \\
(.041)\end{array}$ & $\begin{array}{l}0.069 \\
(.043)\end{array}$ & $\begin{array}{l}0.049 \\
(.051)\end{array}$ \\
\hline $\begin{array}{l}\text { Number of observations } \\
R^{2}\end{array}$ & $\begin{array}{l}1,865 \\
0.018\end{array}$ & $\begin{array}{l}1,798 \\
0.016\end{array}$ & $\begin{array}{l}1,375 \\
0.018\end{array}$ & $\begin{array}{l}1,865 \\
0.019\end{array}$ & $\begin{array}{l}1,798 \\
0.017\end{array}$ & $\begin{array}{l}1,375 \\
0.018\end{array}$ \\
\hline
\end{tabular}

Bold indicates significance at $10 \%$. Standard errors in parentheses. Age is measured in decades as deviations from age 40 . $\ln y_{t}$ is normalized so that it has mean 0 . This means that the constant should be interpreted as the consumption growth rate of a 40-year-old with no change in household size, no change in employment status, and average lagged income.

imputed) information on borrowing constraints. ${ }^{11}$ Columns 4 through 6 repeat the pattern of columns 1 through 3 , while augmenting the regression specification with employment growth to allow for leisure nonseparabilities.

The first column of table 5 indicates statistically (and economically) significant excess sensitivity in our full sample. The fourth column shows that this result is robust to conditioning on employment growth to capture leisure nonseparabilities. The second column shows that the excess sensitivity of consumption growth to lagged income remains when we delete those reporting a binding constraint from the sample, and column 3 indicates that it remains even when we delete all those who report they could not borrow. Thus, we find excess sensitivity of consumption growth to lagged income that cannot be explained by either labor nonseparabilities or currently binding credit constraints.

However, it is important to consider the magnitudes of these effects. In our sample, the standard deviation of the logarithm of lagged income is 0.6 . The coefficients on the logarithm of lagged income in columns 1 through 3 are between -0.07 and -0.08 . Thus, a 1 standard deviation decrease in income at interview 1 raises subsequent consumption growth by 4 or 5 logarithm points. In contrast, in table 4 , the difference between the consumption growth rate of those reporting a binding borrowing constraint and the rest of the sample is 25 logarithm points, or five to six times as large. Thus, the variation in consumption growth rates across groups (constrained versus unconstrained) is much larger than the variation with lagged income within groups. Really rapid consumption growth, and hence very large welfare losses, are associated with binding credit constraints.

\footnotetext{
${ }^{11}$ In addition, Japelli et al. (1998) estimate a switching model, so there is a test for excess sensitivity in both the imputed constrained and imputed unconstrained groups. Sample size precludes us from estimating the regression within the reported constrained group in a parallel fashion. While our overall sample is of reasonable size, there are simply too few households that report a binding constraint.
}

TABLE 6.-FINANCIAL HARDSHIP ON JOB LOSS

\begin{tabular}{lccc}
\hline \hline & $\begin{array}{c}\text { Raw } \\
\text { Proportion }\end{array}$ & \multicolumn{2}{c}{ Probit Marginal Effects } \\
\hline No credit demand & 0.519 & \multicolumn{2}{c}{ (omitted group) } \\
Successful applicant & 0.556 & 0.037 & 0.029 \\
& & $(.032)$ & $(.034)$ \\
Unsuccessful applicant & 0.755 & $\mathbf{0 . 2 3 1}$ & $\mathbf{0 . 1 9 0}$ \\
& & $(.045)$ & $(.050)$ \\
Discouraged & 0.807 & $\mathbf{0 . 2 8 0}$ & $\mathbf{0 . 2 4 2}$ \\
& & $(.037)$ & $(.017)$ \\
Controls & - & None & Full \\
Number of observations & & 1,477 & 0.080 \\
$R^{2}$ & & 0.027 & 0.080 \\
\hline
\end{tabular}

Association of Self Reported Financial Hardship (Resulting from Job Loss) with credit status. Raw percentages and marginal effects from probit. Standard errors in parentheses. Bold indicates significance at $10 \%$. "No credit demand" means did not apply for credit (between job loss and first interview) and not discouraged. The full set of controls is the set used in table 2: gender, a spline in age, education dummies, discouraged. The full set of controls is the set used in table 2: gender, a spline in age, education dummies,
spouse present, children present, visible minority, reason for job loss (quit, fired, ill health), home ownership, spouse present, children present, visible minority, reason for job loss (quit, fired, ill health), hon
outstanding mortgage, spouse employed, liquid assets, other debt, and whether employed.

Following the theoretical discussion in section 2, we have interpreted the high consumption growth rates of those reporting binding borrowing constraints as indicating significant welfare losses. Our data contain self-reports (at the first interview, three quarters after job loss) of whether the job loss was associated with financial hardship. ${ }^{12}$ We now use these reports as the second assessment of the costs of a binding borrowing constraint. Table 6 reports estimates of probit models for this binary outcome (where a 1 indicates that the job loss was associated with financial hardship and a 0 otherwise.) We relate this outcome to measures of credit constraints and other characteristics of the respondent and her household. (The additional controls are the same as in table 2.)

We focus here on the objective credit constraint measures as these pertain to the whole period between the job loss and the first interview (as opposed to a point in time). We use these to divide our sample into four groups: those who had no credit demand (neither applied nor discouraged), successful applicants, unsuccessful applicants, and those who

\footnotetext{
12 The question was: "Has the loss of the job on [DATE] been a financial hardship for your household?"
} 
were discouraged from applying by the expectation of being declined. Following table 1, those in the latter two groups are considered to have experienced a binding borrowing constraint.

The first column shows the raw fractions reporting financial hardship in the four groups. These are substantially higher in the constrained groups (unsuccessful applicants and discouraged). The second column shows the marginal effects from a probit with no additional controls (just the group dummies). This shows that the differences in the prevalence of financial hardship between constrained and unconstrained groups are statistically significant. In the third column, we add additional controls. This leads to little change in the marginal effects (or their statistical significance). Thus, experiencing a binding borrowing constraint is associated with very rapid subsequent consumption growth and a much greater probability of reporting that the job loss was a financial hardship.

\section{Conclusion}

Borrowing constraints can generate consumption growth by two distinct mechanisms: currently binding borrowing constraints may lower current consumption directly, while the possibility of binding constraints in the future can lower current consumption by raising the value of precautionary saving. Unusually rich data have allowed us to assess the relative importance of these channels for recent job losers.

Our analysis reveals that a small fraction of job losers (less than one in six) experiences a binding borrowing constraint in the year after job loss. Relative to all job losers, this group has lower education and is more likely to belong to a visible minority. They subsequently exhibit very rapid consumption growth. We interpret this as a failure to smooth consumption, with significant welfare costs. This interpretation is corroborated by self-reports of financial hardship associated with job loss.

Among job losers, excess sensitivity of consumption to current income is not limited to those who report a binding borrowing constraint. However, the difference in consumption growth rates between the constrained and unconstrained group is an order of magnitude larger than the excess sensitivity in the latter group. The largest welfare losses are overwhelmingly concentrated among the small group who hit a binding constraint.

We would expect the incidence of borrowing constraints to be higher among job losers than among those in continuing employment; consistent with this, we find that for recent job losers, failure to obtain rapid reemployment is a significant predictor of experiencing a binding constraint. However, even among this group, the fraction who experience a binding constraint is small. The very rapid consumption growth of this small group as they recover from job loss suggests a failure of private and public smoothing mechanisms and significant welfare losses. At a macrolevel, this group is likely to be small and account for very little of aggregate wealth and consumption. To understand the importance of credit constraints more generally, we would need information on other groups where such constraints may be important, such as the self-employed, and at points in the life cycle when constraints were more likely to be binding, such as among college attendees.

\section{REFERENCES}

Bloemen, H. G., and E. G. F. Stancanelli, "Financial Wealth, Consumption Smoothing, and Income Shocks Arising from Job Loss," Economica 72 (2005), 431-452.

Browning, M., and T. F. Crossley, "Unemployment Benefit Levels and Consumption Changes," Journal of Public Economics 80 (2001), $1-23$.

"Shocks, Stocks and Socks: Smoothing Consumption over a Temporary Income Loss," Journal of the European Economic Association 7 (2009), 1169-1192.

Browning, M., T. F. Crossley, and G. Weber, "Asking Consumption Questions in General Purpose Surveys," Economic Journal 113 (2003), F540-F567.

Carroll, C., "A Theory of the Consumption Function, with and without Liquidity Constraints," Journal of Economics Perspectives 15 (2001), 23-46.

Dynarski, S., and J. Gruber, "Can Families Smooth Variable Earnings?" Brookings Papers on Economic Activity 1997 (1997), 229-303.

Gross, D., and N. Souleles, "Do Liquidity Constraints and Interest Rates Matter for Consumer Behaviour? Evidence from Credit Card Data," Quarterly Journal of Economics 117 (2002), 149-185.

Hall, R., and F. Mishkin, "The Sensitivity of Consumption to Transitory Income: Estimates from Panel Data on Households," Econometrica 50 (1982), 461-481.

Jappelli, T., "Who Is Credit Constrained in the U.S. Economy?" Quarterly Journal of Economics 105 (1990), 219-234.

Jappelli, T., J.-S. Piske, and N. Souleles, "Testing for Liquidity Constraints in Euler Equations with Complementary Data Sources," this REVIEW 80 (1998), 251-262.

Johnson, D., J. Parker, and N. Souleles, "Household Expenditure and the Income Tax Rebates of 2001," American Economic Review 96 (2006), 1589-1610.

Leth-Petersen, S., "Intertemporal Consumption and Credit Constraints: Does Consumption Respond to an Exogenous Shock to Credit?" American Economic Review 100 (2010), 1080-1103.

Lucas, R. E., Jr., Models of Business Cycles (New York: Basil Blackwell, 1987).

Mayer, S. E., and C. Jencks, "Poverty and the Distribution of Material Hardship," Journal of Human Resources 24 (1989), 88-113.

Runkle, D. E., "Liquidity Constraints and the Permanent Income Hypothesis: Evidence from Panel Data," Journal of Monetary Economics 27 (1991), 73-98.

StataCorp, Stata Base Reference Manual (College Station, TX: Stata Press, 2009).

Sullivan, J. X., "Borrowing during Unemployment: Unsecured Debt as a Safety Net," Journal of Human Resources 43 (2008), 383-412.

Zeldes, S., "Consumption and Liquidity Constraints: An Empirical Investigation," Journal of Political Economy 96 (1989), 305-346.

Ziliak, J. P., "Does the Choice of Consumption Measure Matter? An Application to the Permanent-Income Hypothesis," Journal of Monetary Economics 41 (1998), 201-216. 
Copyright of Review of Economics \& Statistics is the property of MIT Press and its content may not be copied or emailed to multiple sites or posted to a listserv without the copyright holder's express written permission. However, users may print, download, or email articles for individual use. 